\title{
OS TRABALHADORES E SUAS VIVÊNCIAS COTIDIANAS \\ Dos tempos de trabalho e de não-trabalho
}

\section{Ana Claudia Moreira Cardoso}

\section{Apresentação}

Que mudanças estão ocorrendo no tempo de trabalho e de não-trabalho na sociedade brasileira? Quais as principais características do tempo de trabalho e do tempo de não-trabalho? Como os sujeitos vivenciam esses tempos sociais? Nos locais de trabalho, o que tem sido discutido e o que não é colocado como objeto de negociação coletiva? Quais as discussões e as disputas em torno desses tempos no plano macrossocial e político? Quando analisamos sociedades diferentes, vemos culturas temporais distintas? Para onde vai o tempo de trabalho?

Essas são algumas das indagações que orientam a análise elaborada neste texto que tem como foco a temática do tempo de trabalho. ${ }^{1}$ Tema este anti-

Artigo recebido em novembro/2008

Aprovado em novembro/2009 go mas fundamental para se compreender o funcionamento das sociedades, visto ser um de seus elementos estruturais. Nesse momento, o tempo de trabalho sofre contínua intensificação e flexibilização, enquanto o movimento histórico de redução da jornada de trabalho tem evoluído pouco. Além disso, o processo de separação entre os tempos e os espaços de trabalho e de não-trabalho vem sendo substituído por um movimento contrário, de reaproximação, de forma que a definição de onde cada um começa e termina está cada vez mais fluida (Freyssenet, 1994; Zarifian, 1996).

Vê-se, ainda, a fragmentação e a individualização do tempo dedicado ao trabalho e o surgimento de uma pluralidade de novos tempos de trabalho. Fragmentação e individualização causadas, sobretudo, pela crescente flexibilização que coloca esses tempos cada vez mais em total assincronia em relação aos outros tempos sociais - como o da família, do lazer, do amor, da educação, entre outros. 
É nesse contexto de intensas transformações que discuto o tempo de trabalho e de não-trabalho, tendo como objetivo compreender como se dão as vivências temporais cotidianas dos trabalhadores. $\mathrm{E}$ para melhor compreender tais vivências, elas serão contextualizadas tanto no plano macrossocial - das mudanças no tempo e no trabalho na sociedade atual -, como no microorganizacional - das transformações nas relações sociais nos locais de trabalho. Neste caso, estudo a Volkswagen do Brasil, em sua unidade de produção do ABC (São Paulo). Vale ressaltar, entretanto, que a empresa é apenas a porta de entrada para se compreender o que se passa no âmbito mais amplo, das transformações na cultura temporal da sociedade brasileira.

Neste artigo, inicio com uma breve análise sobre o tempo de trabalho na sociedade contemporânea, destacando a sociedade brasileira. Num segundo momento, discuto, também de forma breve, o contexto das negociações na Volkswagen do ABC para, em seguida, analisar como os trabalhadores vivenciam os tempos dentro e fora do local de trabalho. Dessa forma, realizo um conjunto analítico que conjuga visôes macro e micro, considerando a relação recíproca de influência entre as construções sociais no âmbito do espaço fabril e da sociedade como um todo.

\section{Os tempos na sociedade contemporânea}

Ter como foco de análise a temática do tempo de trabalho e de não-trabalho justifica-se pelo fato de a estruturação da vida social se efetivar, fortemente, por sua mensuração, definição e rotinização (Elias, 1998), principalmente a partir do advento das sociedades industriais (Thompson, 1967; Hobsbawm, 2000). Por outro lado, analisar a definição dos tempos de trabalho e de não-trabalho como "práticas sociais ordenadas no espaço e no tempo" (Giddens, 2003) explicitou dois aspectos complementares e indissociáveis. Um refere-se ao movimento estrutural no sentido da uniformização do tempo social, com o crescimento da organização racional e burocrática (Giddens, 1995), tendo como objetivo ordenar as atividades individuais de modo coletivo. O segundo trata do modo como cada ser humano vivencia e experimenta, de maneira específica, a sua temporalidade social.

Dessa forma, considero o Tempo uma experiência subjetiva, antes mesmo de constituir-se como objeto de reflexão, medida de duração ou objeto de poder. Assim, mesmo que o Tempo seja apreendido e percebido como único, preciso, uniforme e igual em todos os lugares, quando são analisadas as vivências dos sujeitos, essa possível e aparente homogeneidade cede lugar à explicitação de uma diversidade de tempos sociais - tempos da escola, da família, do lazer, do amor, do trabalho e do descanso. Mais ainda, revela-se toda a diversidade de vivências existentes em relação a um mesmo tempo social, levando à visualização de tempos de trabalho, tempos de lazer, tempos do amor, sempre no plural. Ou seja, o tempo é, em cada sociedade, experiência, representação, norma, valor, instituição e referência.

De modo que, ao olharmos para o tempo de trabalho, um tempo dominante desde a Revolução Industrial, veremos que uma parte deste é mensurável - o tempo do calendário, dos relógios de ponto, dos minutos e dos segundos - e, simultaneamente, outra parte que não é possível ser contabilizada, que é a maneira pela qual cada um vive subjetivamente essas medidas. Desde a década de 1980, notamos um intenso movimento de flexibilização desse tempo mensurável, a partir de alterações na quantidade e na forma do tempo de trabalho. Por outro lado, pouco sabemos a respeito das vivências dos trabalhadores no que se refere a tais mudanças.

Em diversos países, como Espanha, Inglaterra, Alemanha e Itália, o movimento de flexibilização do tempo de trabalho é uma iniciativa empresarial, mas também advém de forte intervenção estatal, no sentido de alteração na legislação vigente. Mesmo na França, onde houve intenso processo de negociação para a redução da jornada de trabalho, também podemos observar uma infinidade de iniciativas no sentido da flexibilização do tempo de trabalho por parte das empresas e igualmente pelo Estado (Thoemmes, 2000).

Mispelblom (1999) afirma que este processo de flexibilização do tempo de trabalho leva os trabalhadores, cada vez mais, a perderem o controle da organização de seus tempos sociais, em função 
da fragmentação e da individualização dos tempos dedicados ao trabalho, os quais não estão mais de acordo com as outras temporalidades sociais. Além disso, observa-se um movimento de reaproximação entre o tempo de trabalho e de não-trabalho, tornando cada vez mais fluida a delimitação entre esses tempos. Zarifian (1996) salienta ainda que o tempo de trabalho desenvolvido no local de trabalho se organiza, crescentemente, a partir da transposição do modo de viver o tempo de trabalho doméstico. Ou seja, um tempo caracterizado pela ausência de limites, de controle explícito por parte do outro e sem uma contabilidade detalhada.

Logo, num cenário de mudanças profundas no tempo de trabalho, seria importante repensar a maneira pela qual esse tempo é qualificado e quantificado, assim como o tempo de não-trabalho. Podemos então questionar o significado daqueles tempos nos quais as pessoas realizam tarefas ainda relacionadas com o trabalho, mesmo fora da jornada regular ou extraordinária. Questionar o conceito predominante em que o tempo de trabalho é pensado apenas como aquele contido em uma jornada contratada, remunerada e restrita a um determinado locus (Guedj e Vindt, 1997), como se todo o tempo para além deste fosse um tempo de não-trabalho (Dal Rosso, 1996). Assim, considero que o tempo dedicado ao trabalho extrapola, e muito, aquele contido em uma jornada.

Dessa forma, o tempo dedicado ao trabalho incluiria, por exemplo, as horas gastas com o deslocamento dos indivíduos da casa ao trabalho, o crescente tempo dedicado às atividades de qualificação, cada vez mais exigidas pelas empresas, e as horas de sobreaviso. Incluiria ainda o tempo dedicado às tarefas levadas para casa, que, na maior parte das vezes, ocorre de maneira informal, fortemente facilitadas pelo uso da internet e do celular.

Caberia refletir também sobre o tempo em que os trabalhadores passam a buscar soluções para o processo de trabalho, principalmente a partir da ênfase dada à sua participação. Por exemplo, a partir das "caixas de sugestão", dos CCQ's ou dos grupos semi-autônomos, levando-os a permanecerem "plugados" no trabalho mesmo estando distantes da empresa. Isto porque, de acordo com Hirata (1987), a gestão baseada na integração dos traba- lhadores pela técnica da participação requer um grande número de horas de atividades e estudos desenvolvidos fora das horas contidas na jornada e no espaço de trabalho.

Para dar continuidade a essa discussão, no item a seguir analisarei como tais mudanças nos tempos de trabalho têm se realizado em uma sociedade concreta, num determinado momento histórico: o Brasil a partir dos anos de 1990 .

\section{O tempo de trabalho no Brasil}

Para melhor compreender o processo de construção social do tempo de trabalho e de não-trabalho no Brasil, proponho uma breve análise comparativa com uma cultura temporal distinta, que é o caso francês, onde essa temática esteve em forte evidência em função de intensas discussões e negociaçôes em torno da redução do tempo de trabalho envolvendo diversos atores sociais ao longo de sua história.

A análise da experiência francesa não só contribui para a reflexão sobre a redução da jornada de trabalho ocorrida no final dos anos de 1980, mas também no momento atual e futuro ao explicitar as diversas formas pelas quais o empresariado busca sua anulação. Seja pelo aumento da hora-extra; pela implementação de mudanças técnico-organizacionais que busquem intensificar o ritmo de trabalho; pela ampliação da flexibilização do tempo de trabalho; ou, ainda, pela expulsão do tempo de trabalho de momentos utilizados pelos trabalhadores para pausas individuais e coletivas ou para a troca de roupa. Explicita, além disso, o papel fundamental do Estado nesse processo, sem menosprezar, por outro lado, a importância da pressão social e política.

Acerca do tempo de trabalho, Brasil e França revelam-se contextos sociais muito diferentes em relação aos macro e microespaços de negociaçōes na política ou dentro das empresas. No entanto, em ambos os casos observaram-se aspectos que parecem ser comuns à construção temporal das sociedades contemporâneas, a saber: a pressão patronal para flexibilizar o tempo de trabalho, a partir das necessidades da produção, e também para retomar o controle do tempo do trabalhador dentro e fora 
dos locais de atividade profissional. Ademais, o desemprego tem sido fator relevante no processo de negociação coletiva, pressionando os trabalhadores a abrirem mão de direitos conquistados e a aceitarem as iniciativas de flexibilização e intensificação do tempo de trabalho por parte das empresas.

É o que se constata, no Brasil, a partir de meados dos anos de 1990, quando fortes mudanças no mundo do trabalho foram realizadas por parte das empresas e do governo, no sentido da desregulamentação pela via da flexibilização seja da remuneração e da forma de contratação, seja do tempo de trabalho. Em 1998, por exemplo, ampliou-se o prazo de compensação das horas extras de uma semana para um ano, o chamado "banco de horas", alterando completamente a relação do trabalhador com o seu tempo de trabalho e de não-trabalho.

Todavia, se considerarmos a concepção de flexibilidade como a capacidade de responder efetivamente a circunstâncias de mudança (Salerno, 1998), percebemos que ela está presente desde há muito tempo na sociedade brasileira, tanto pelo fato de as empresas poderem utilizar hora extra, contrato de trabalho para tempos específicos, trabalho em equipes, período noturno, férias coletivas, redução do salário e da jornada de trabalho, como em virtude da facilidade promovida em processos de demissão.

A partir dos anos de 1990, no Brasil, presenciamos não apenas um processo de intensificação do tempo de trabalho, de altas taxas de desemprego, de estagnação da redução da jornada de trabalho, mas também uma tendência à extensão da jornada de trabalho. Um dos exemplos é o crescimento do número de trabalhadores que passaram a realizar horas extras desde $1988 \mathrm{em}$ todos os setores da economia; outro é a pressão patronal no sentido de aumentar a jornada em setores onde esta é inferior a 44 horas, como no setor bancário, ou a redução do número de equipes em turnos de revezamento, buscando a ampliação das jornadas semanais médias (Cardoso et al., 2002).

Mas, se de um lado as açôes do governo e dos empresários buscam flexibilizar e ampliar o tempo em que os trabalhadores estão à disposição do capital, de outro, a ação do movimento sindical continua sendo de limitação ou redução da jornada de traba- lho. Tais açôes desenvolvem-se tanto em locais de trabalho, como pela elaboração de propostas mais abrangentes de mudanças na legislação. No âmbito nacional, a partir de 2003, as Centrais Sindicais brasileiras iniciaram uma campanha nacional pela redução da jornada de trabalho, sem redução de salários intitulada "Reduzir a Jornada de Trabalho para Criar Empregos", reivindicando redução da jornada de trabalho para 40 horas por semana, sem redução de salários e limitação de utilização do banco de horas e da hora extra.

As centrais sindicais têm procurado, nesta campanha nacional, o engajamento do governo, pois entendem que, assim como o processo de negociação francesa, esta pauta será conquistada somente a partir de mudanças na legislação. Entretanto, até o final de 2009, observamos que essa campanha, apesar de já ter criado e ampliado alguns espaços de discussão, ainda não se traduziu em uma mudança na legislação. Resta saber se tal embate resultará ou não em um novo desenho para o tempo de trabalho no Brasil e, conseqüentemente, para o tempo de não-trabalho.

Assim, a partir da década de 1990 a discussão sobre a redução do tempo de trabalho tem se dado unicamente em categorias profissionais com forte organização sindical, como é o caso dos trabalhadores da Volkswagen. Entretanto, mesmo neste caso, a negociação da redução do tempo de trabalho tem sido vinculada à sua flexibilização.

\section{Os tempos de trabalho na empresa}

Nesta seção, com base em uma análise centrada na Volkswagen, localizada em São Bernardo do Campo (ABC) - São Paulo, ${ }^{2}$ discutirei como as mudanças no tempo de trabalho se dão dentro de uma empresa específica. Vale ressaltar, entretanto, que a empresa é apenas a porta de entrada para dar continuidade à compreensão do que se passa no âmbito mais amplo das transformações na cultura temporal da sociedade brasileira. A escolha da Volkswagen do $\mathrm{ABC}$ deve-se ao fato de ser uma empresa que realiza diversas inovações em termos de relaçôes de trabalho, alterando completamente os ritmos e os modos de utilização do tempo. 
A história da Volkswagen no Brasil pode ser dividida em quatro momentos, se tomarmos como referência as mudanças ocorridas no tempo de trabalho. O primeiro inicia-se em 1953 e se estende até final dos anos de 1970, sendo caracterizado por um movimento de expansão da empresa, da produção e também do tempo de trabalho. $\mathrm{O}$ segundo, abrange o final dos anos de 1970 e meados da década seguinte, sendo caracterizado pelo grau de conflito mais acentuado, num contexto de reafirmação do movimento sindical como ator político, quando temos o primeiro embate em torno da redução da jornada de trabalho.

No terceiro momento, entre os anos de 1986 e 1995, ocorre a criação da Autolatina com a fusão da Volkswagen e da Ford, a implantação de mais uma etapa de automação e mudanças nos métodos de gestão da produção e do trabalho. Como salienta Salerno (1998), até o início dos anos de 1990 o nível de automação da Autolatina não era muito alto. Por outro lado, diversas mudanças organizacionais foram implementadas e tiveram forte impacto sobre o tempo de trabalho. $\mathrm{O}$ autor salienta ainda que este período é caracterizado pela extrema flexibilidade via utilização de horas extras, trabalhos em turnos, trabalho noturno, férias coletivas obrigatórias, compensação compulsória dos feriados, multifunção, transferência de trabalhadores entre os setores e entre as diferentes plantas.

No quarto momento, a partir de meados da década de 1990, há um forte processo de negociação em torno do tempo de trabalho, o que incluiu a discussão da redução da jornada de trabalho e sua flexibilização num contexto em que a empresa considerava o fechamento da planta do ABC. A análise das negociações explicita uma troca entre a flexibilização do tempo de trabalho demandada pela empresa e a redução do tempo de trabalho reivindicada pelos trabalhadores. Entretanto, já a partir de 1998, a questão da redução da jornada de trabalho desaparece do processo de negociação, o qual passa a se dar em torno da troca entre a manutenção do emprego e a flexibilização do tempo de trabalho. ${ }^{3}$

Vale ressaltar, entretanto, que em todo o processo de negociação ocorrido nos anos de 1990, a discussão sobre o emprego sempre esteve presente, pois, a cada momento em que os trabalhadores re- cusavam uma proposta de flexibilização, a empresa ameaçava ampliar o processo de demissóes, levando os trabalhadores e seus representantes a cederem novamente às pressōes. Considerando que este não é um caso isolado, ao iniciar os processos de negociação a partir da ameaça de desemprego, as empresas reforçam e ampliam a desigualdade entre as partes, possibilitando um resultado muito mais favorável a seus interesses e objetivos.

\section{As vivências dos trabalhadores}

Com base nos relatos dos trabalhadores, veremos como as situaçōes dentro da empresa - artefatos tecnológicos, mudanças na organização do trabalho, na gestão das pessoas ou na jornada de trabalho são experimentadas cotidianamente e quais desses elementos são por eles considerados os principais definidores do tempo de trabalho e de não-trabalho. Analisar o tempo de trabalho em um espaço microorganizacional específico aportou elementos para melhor compreender os inúmeros fatores que podem alterar esse tempo, pois, se num primeiro momento poderíamos pensar que o impacto sobre ele ocorreria apenas com as mudanças diretas na jornada de trabalho, constatamos a diversidade de aspectos a serem considerados.

Assim, no caso da Volkswagen do ABC, algumas mudanças tiveram impactos diretos e explícitos no tempo de trabalho e, na maior parte das vezes, foram objeto de demanda sindical para a negociação, como redução da jornada de trabalho, hora extra, pausas e flexibilização do tempo de trabalho. Mas há outras mudanças que afetam este tempo de forma menos explícita, podendo ser subdivididas em dois tipos: as que não foram objeto de negociação coletiva, como a maior parte das mudanças tecnológicas e algumas organizacionais - por exemplo, a implantação do just in time -; e as que foram objeto de negociação, porém sem mencionar a questão do tempo de trabalho. O Plano de Cargos e Salários (PCS) é um exemplo nesse sentido, pois embora tenha sido objeto de grande debate, não se discutiram os impactos que a multitarefa nele prevista teria sobre o tempo de trabalho; outro exemplo foi a negociação das células de produção, que 
não incluiu itens relacionados com seus impactos sobre o ritmo de trabalho.

A seguir, tratarei dessas mudanças e das vivências dos trabalhadores no que se refere ao tempo, dividindo-as em três partes: as mudanças que se deram diretamente na organização do tempo de trabalho; as mudanças tecnológicas e organizacionais que tiveram impactos diretos no tempo de trabalho e, ainda, os momentos dentro da empresa que não são considerados tempo de trabalho.

\section{Redução e flexibilização}

Entre as mudanças diretas na organização do tempo de trabalho temos aquelas relacionadas com a duração da jornada de trabalho e das pausas individuais e coletivas, bem como as diversas formas de sua flexibilização, como turno de revezamento, hora extra, banco de horas, banco de dias e a "semana Volkswagen".

Desde os anos de 1980, os trabalhadores fazem pressão para a redução da duração do tempo de trabalho e a empresa, em contrapartida, tem buscado meios para compensar essa conquista dos trabalhadores, transformando todos os tempos, ainda contidos na jornada de trabalho, em tempos produtivos. Para isso a Volkswagen tem reduzido as pausas coletivas e individuais e investido em inovaçóes que intensifiquem o ritmo de trabalho.

$\mathrm{Na}$ década de 1990, houve um intenso processo de discussão a esse respeito, quando foi negociada a redução do tempo de 44 para 43 horas semanais, a partir de 1996 , e para 42 horas, a partir do ano seguinte, com margem para sua flexibilização entre 36 e 44 horas. De acordo com um dos negociadores patronais, apesar de a demanda sindical ser para a redução do tempo de trabalho, "como forma de barganha nós acabamos aceitando sua redução, desde que houvesse a possibilidade de uma flexibilização, e essa flexibilização foi traduzida depois num sistema de banco de horas".

A redução das pausas individuais e coletivas tem sido uma prática da empresa desde meados dos anos de 1980, quando os trabalhadores conquistaram a redução da jornada de trabalho. Em meados da década seguinte, em meio ao processo de negociação das células de produção, a empresa criou o posto de monitor, trazendo novamente à tona a questão da redução. $\mathrm{O}$ monitor teria, como uma de suas funções, substituir pontualmente o trabalhador no momento em que este necessitasse sair da linha de produção para fazer uma pausa, mantendo, assim, seu fluxo contínuo. Entretanto, os trabalhadores salientam que a redução de pessoal faz o monitor ocupar um único posto de trabalho o dia todo, de forma que raramente ele está livre para substituir pontualmente um trabalhador:

[...] você tem que ficar segurando para ir ao banheiro. Ou então, a gente que tem mais um pouco de consciência, abandona a linha lá, né, abandona o setor e vai no banheiro e aí passam cinco, sete, oito carros sem fazer. Porque o certo é que tivesse um monitor disponível pra qualquer trabalhador que fosse no banheiro, ir no médico, alguma doença, ele sair de imediato, não pode ficar esperando [Otelo].

Além da duração da jornada de trabalho e das pausas, outra mudança direta no tempo de trabalho se refere à sua flexibilização. Entre as formas mais antigas estão os turnos de trabalho e a hora extra; entre as mais recentes, há o banco de horas, o tempo parcial, e, no caso específico da Volkswagen, o banco de dias e a "semana Volkswagen".

Em relação ao trabalho em turnos de revezamento, todos os trabalhadores entrevistados foram unânimes em dizer que a experiência sempre foi negativa, pois a alternância de horários acabava por destruir a própria saúde e as relações sociais. ${ }^{4}$ O turno de revezamento, de acordo com os trabalhadores, assim como o trabalho noturno, é um elemento a balizar fortemente suas vivências, considerando que a organização do trabalho nesses horários atípicos são as formas que mais desorganizam suas vidas fora do local de trabalho. Exigem uma equação temporal - pessoal e familiar - para acomodar, da melhor maneira possível, os diversos tempos pessoais e sociais, sujeitos aos horários atípicos de trabalho.

A escolha do trabalho noturno é, na maior parte das vezes, uma solução individual dirigida a resolver problemas financeiros, visto o atrativo representado pelo adicional noturno. Mas, como bem 
salienta Lallement (2003), decidir por trabalhar à noite é muito diferente de viver cotidianamente este trabalho. Para grande parte dos trabalhadores que dizem não ter uma boa adaptação ao trabalho noturno, sobretudo em função de problemas com o sono, alimentação e distanciamento em relação à família e aos amigos, este trabalho é vivido de forma muito negativa. Nesse caso, o que os trabalhadores mais relatam é a falta de disposição, tanto para o tempo de trabalho como para o tempo de não-trabalho.

Ressaltam a queda do rendimento profissional, da qualidade do trabalho, do aumento do cansaço, do mau humor e maior incidência de acidentes e doenças ligadas ao trabalho. $\mathrm{Na}$ vida pessoal, fazem referência à sua total desorganização, à alteração na quantidade e na qualidade das atividades fora da fábrica (com a família, os amigos, com os outros momentos de lazer) e à dificuldade de acomodar todos os tempos sociais.

Além do turno de trabalho, a hora extra é outra antiga forma de flexibilizar o tempo na fábrica. Muitos trabalhadores da Volkswagen relataram o uso freqüente dessa prática, o que é bastante reivindicado pela empresa. Assim como o trabalho noturno, abre-se aí uma possibilidade individual de o trabalhador aumentar sua remuneração. Entretanto, os trabalhadores frisam que há uma grande diferença entre fazer hora extra para ganhar mais dinheiro e gostar de trabalhar a mais:

Tem aquele que briga com o chefe porque não tem hora extra, mas são raros, não é assim, a grande maioria, todos eles gostam de ficar em casa. Agora, para você ficar em casa, ter um lazer, você tem que ter dinheiro [Eron].

Alguns comparam essa prática com o banco de horas, implantado na empresa a partir de 1995. Ressaltam que com o banco de horas houve certamente uma redução dos custos da empresa, uma vez que se deixa de pagar uma parte do adicional de hora extra. o que, para os trabalhadores resultou na redução da remuneração. Afinal, o objetivo da realização da hora extra é justamente o adicional extra. Segundo relato do gerente de RH da Volkswagen, além da redução de custo, em função do novo controle o banco de horas possibilitou a identificação dos setores com problemas de produção e onde, conseqüentemente, havia acúmulo de hora extra, explicitando e formalizando a demanda nesse sentido, que antes ocorria informalmente em função de acertos diretos entre o chefe e o trabalhador.

Assim, houve uma intensificação na flexibilização do tempo de trabalho quando às antigas formas de flexibilização foram somadas novas, como o banco de horas, o banco de dias 5 e a "semana Volkswagen". Mas quem decide sobre a flexibilização? Essa é a pergunta básica para iniciar uma discussão a respeito. Afinal, como bem salientado por Grossin (1991), entre flexibilidade e rigidez, poucos optariam pela segunda, o que torna relevante saber quem decide.

Segundo diversos dirigentes sindicais, a implantação do banco de horas gerou muitas reclamações por parte dos trabalhadores em função tanto da redução da remuneração, como da dificuldade em utilizá-lo quando necessário. Atualmente, são poucos os que se posicionam explicitamente contra esse tipo de organização, apesar da dificuldade em utilizar o saldo positivo quando necessitam e da existência de um saldo negativo muito grande, por causa da baixa demanda de trabalho em determinados momentos. Isso obriga, por outro lado, a trabalhar quando a empresa solicita, atrapalhando toda a vida fora da fábrica.

O banco de horas acabou onerando o funcionário. Porque o funcionário, como eu te falei, ele está devendo horas, sem ter opção de estar devendo ou não. Quer dizer, aumentou a demanda de mercado, a fábrica convoca, você tem que ir, sendo que pode ser um dia que você pode estar usando para outra coisa ou ter programado alguma coisa... [Anderson].

Outra forma recente de flexibilização foi a criação da "semana Volkswagen" a partir de 1998, como já comentado. Trata-se da redução de um dia da semana de trabalho, que passou a ser de segunda a quinta, e redução de $15 \%$ na Participação nos Lucros e Resultados - PLR. Até hoje, isso é motivo de muita reclamação. 
Porque a semana reduzida a gente perde, e o intuito da gente aqui é ganhar dinheiro. Ninguém é relógio, a gente trabalha por querer ganhar grana. Então você fica em casa e sabendo que você não está recebendo, e às vezes você não tem o que fazer, porque você já está programado para isso, e às vezes vem assim, fica um dia perdido [Marcos].

Mas, assim como ocorre em relação à "aceitação" do banco de horas, aceitar a "semana Volks" significava evitar um processo maior de demissão, como ressalta um trabalhador:

[...] foi muito interessante porque a gente evitou bastante demissão aqui na Volkswagen. [...] Eu optaria por continuar com a "semana Volks", mesmo com a redução da PLR se fosse também pra abrir mais vagas no mercado e fosse mesmo pra evitar demissão, né. Porque é melhor você trabalhar de segunda a quinta do que você ser demitido [Edgar].

Em 2000, durante o processo de negociação, os trabalhadores se recusaram a renovar o acordo que englobava o banco de horas, o banco de dias e a "semana Volkswagen". Todavia, sem a renovação do acordo, em 2001, como já tinha ocorrido em 1998, a Volkswagen anunciou a demissão, forçando a abertura de um novo processo de negociação (Barbosa, 2002). Este processo resultou na retomada do banco de horas e da "semana Volkswagen", em troca da manutenção do emprego até 2006.

Em suma, desde a década de 1990 pode-se observar claramente a flexibilização do tempo de trabalho sendo utilizada como moeda de troca para os trabalhadores alcançarem seja a redução da jornada de trabalho, seja a garantia de emprego.

\section{Organização do trabalho e intensificação do tempo}

Analiso aqui como muitas mudanças realizadas na organização do trabalho tem impactos diretos no tempo de trabalho, o qual é afetado não apenas pelas mudanças diretas - como vimos - mas também por transformações técnico-organizacionais e de gestão.
Um dos primeiros elementos que me chamou a atenção nas falas dos trabalhadores foi a manutenção da linha de produção como um dos maiores definidores do tempo de trabalho. Para eles, a linha ainda significa ritmo imposto, intenso, contínuo, repetitivo, minuciosamente controlado e, muitas vezes, causador de desconforto, dor e doenças. Ritmo que continua desconsiderando as necessidades básicas, como beber água, ir ao banheiro, conversar com colegas, aliviar dores, cansaço, ou ainda as diferentes disposições ao longo do dia. Um tempo de trabalho que influencia a vida fora da empresa, como relata um dos trabalhadores entrevistados, contratado em meados da década de 1980:

Nessa época a Volkswagen produzia quatrocentos, quinhentos carros por turma, então você não tinha tempo para conversar, não tinha tempo para tomar café, não tinha tempo para ir ao banheiro, não tinha tempo para nada, você saía dali arrasado. Chegava em casa, eu não vou falar que era estressado para não brigar, chegava cansado mesmo, não tinha mais ânimo para nada. Era chegar, tomar um banho, sentar no sofá, assistir televisão ali e acordar no outro dia para a mesma coisa [Aldo].

Todo o desgaste vivido em nome da produção influencia sobremaneira o tempo de não-trabalho, resultando, ao fim da jornada, estresse, desânimo, uma interferência direta na saúde e na vivência cotidiana dos trabalhadores. Os problemas causados pelo trabalho exaustivo na linha de montagem mantêm-se no contexto atual, mas com uma nova cara. Muitos reclamam que não conseguem, na nova linha do Pólo e do Fox, ter tempo livre para ir ao banheiro, tomar café ou descansar um pouco, sendo que, vale lembrar, o intervalo coletivo formal é também cada vez menor. Trata-se, portanto, de uma redução da pausa informal do trabalho possibilitada por uma nova maneira de funcionamento da nova linha de produção. Há também nessa nova linha um sentimento de isolamento em relação aos colegas, uma vez que os trabalhadores ficam muito distantes uns dos outros, dificultando a conversa e, em contrapartida, aumentando o tempo produtivo. 
Mas aqueles que não trabalham mais em uma dessas linhas dizem preferir o trabalho atual, porque demanda maior responsabilidade, possibilita maior liberdade, ainda que o tempo seja tão corrido quanto o da linha de produção. Como ressalta um trabalhador da logística: "É corrido, mas você faz seu tempo". Assim, vemos que a linha, um dos mais importantes artefatos tecnológicos, símbolo da "era fordista", continua a afetar fortemente a vivência do tempo de trabalho daqueles que a ela estão submetidos.

Se, de um lado, o trabalho na linha impõe um ritmo determinado, contínuo, repetitivo e intenso, de outro, também as mudanças organizacionais e gerenciais acabam por ditar uma frequêencia de trabalho cada vez mais alucinante. Assim, setores como a linha de montagem e a ferramentaria, que consistiam duas realidades extremas e opostas em termos de autonomia em relação ao tempo, hoje em dia têm se aproximado bastante. E esta aproximação não se dá porque os trabalhadores da linha conquistaram maior liberdade, mas porque os ferramenteiros passaram a ter menor liberdade e autonomia. As recentes mudanças em setores onde os trabalhadores controlavam mais seu tempo têm transformado muitos tempos alocados em tempos impostos.

Vemos que foram diversas as mudanças na organização e na gestão dos usos do trabalho, que provocaram importantes transformaçôes no tempo de trabalho. Os operários chamam as inovaçōes de just in time, multitarefa, células de produção, redução do tempo de desenvolvimento e produçãa, metas de produção e absenteísmo em função da PLR. Além disso, elas foram implantadas num contexto de crescente redução do número de trabalhadores.

A redução de pessoal é citada com muita freqüência por muitos trabalhadores, visto que, apesar da garantia de emprego negociada, passou-se a adotar desde 1997planos de demissão voluntária. Após muita discussão, em agosto de 2005, os trabalhadores se mobilizaram para reivindicar a contratação de pessoal, explicitando um problema que há muito os incomodava.

A redução dos prazos para realizar tarefas também é um dos fatores que contribuem na intensificação do tempo de trabalho. Ela é enfatizada por trabalhadores dos setores administrativo, da quali- dade e da ferramentaria, assim como pelos líderes. Muitos dizem que a redução de pessoal, somada à pressão pela redução dos prazos, é totalmente incompatível com a exigência empresarial de melhoria da qualidade dos produtos. Ainda no caso dos ferramenteiros, a terceirização é também muito citada como intensificadora do trabalho, pois há um aumento considerável de peças com defeito. Em suma, essa combinação de fatores não só intensifica como também amplia o tempo de trabalho, dificultando mais e mais a vida fora da fábrica.

Todavia, a mudança que teve maior impacto na intensificação do tempo de trabalho, segundo os operários, foi o revezamento de função - também chamado de polivalência ou multitarefa -, institucionalizado em 1995. No discurso da empresa, essa nova forma de organizar o tempo tinha como objetivo minimizar os problemas de saúde ocasionados pelo trabalho repetitivo, de forma que o trabalhador não ficasse mais diariamente exposto à mesma tarefa. Mas se antes o trabalhador ficava exposto ao mesmo trabalho prejudicial todos os dias, agora, com a polivalência, ele está exposto a um trabalho intenso, em funçôes diferentes, todos os dias.

Isso porque, para viabilizar o aumento da produção em um setor sem a contratação de mais trabalhadores, a empresa desloca trabalhadores de outros setores onde o ritmo de trabalho esteja mais tranqüilo. Se no curto prazo a multitarefa pode atenuar uma dor na coluna, por exemplo, no médio prazo, traz outros problemas de saúde, pois o trabalhador sempre estará em um setor ou função em que a demanda esteja em alta, o trabalho intenso, rompendo assim a lógica de momentos de trabalho mais intensos e outros mais tranqüilos.

Ainda no que se refere à multitarefa, os trabalhadores frisam que não há treinamento para que possam realizar tarefas novas e diferentes, o que pode levar à redução da qualidade do produto. Além disso, leva à intensificação do trabalho para os que precisam treinar o colega que chega no setor, da mesma maneira que exige um maior esforço e mais tempo para quem ainda não domina a função. Estar em uma linha de montagem em que já se conhece o serviço, ou as pessoas, possibilita adiantar o trabalho e, conseqüentemente, cria possibilidade de pequenas pausas. Os trabalhadores entendem, as- 
sim, que a rotatividade de tarefas deixou o trabalho muito mais intenso:

[...] porque antigamente você trabalhava em um posto, hoje você trabalha em três, quatro postos, aquele rodízio que você faz, então a pessoa fica desgostosa. [...] É tendinite, bursite, coluna, dor na coluna [Carlinhos].

A multitarefa, também chamada de "rodízio de função", é mais um artefato gerencial que possibilita à empresa manter um mínimo de trabalhadores empregados, ao ocupar de maneira produtiva todo o tempo do trabalhador. Como bem salienta Grossin (1991), para a empresa, a expansão das tarefas significa aumento de produtividade, economia, aumento da carga de trabalho e redução do número de trabalhadores empregados. Por outro lado, $\mathrm{Du}$ rand (2004) entende que a multitarefa significa, na maior parte das vezes, a ampliação das atividades e não o seu aprofundamento, o que não elimina ou diminui a monotonia do tempo de trabalho. Essas análises ajudam a compreender melhor por que os trabalhadores, de uma forma geral, são contra essa forma de organização e ressaltam a intensificação do tempo de trabalho.

\section{Tempos não considerados como de trabalho}

Além das mudanças envolvidas diretamente no tempo de trabalho e das transformaçôes técnico-organizacionais e de gestão que tiveram como consequiência a intensificação desse tempo, há ainda outra questão que se refere ao tempo em que o trabalhador permanece no local de trabalho e que não é considerado como tempo de trabalho. Os trabalhadores da Volkswagen, por exemplo, permanecem de nove horas e meia a dez horas dentro da empresa. Oito horas referem-se à jornada de trabalho, sendo, portanto, remuneradas; mas o tempo referente ao intervalo de almoço e aquele gasto antes do inicio e depois da jornada de trabalho não são remunerados. ${ }^{6}$

Nesses momentos os trabalhadores, obrigatoriamente, caminham entre a portaria e os setores, e vice-versa, e trocam de roupa. ${ }^{7}$ Esse tempo adicional, e não remunerado, é ainda utilizado por alguns para bater papo e tomar café, mas também para começar a trabalhar quando chegam aos setores, mesmo antes do início oficial da jornada de trabalho. Isso acontece, como frisado pelos dirigentes sindicais, porque a empresa tirou os cinco minutos que os trabalhadores tinham para preparar a linha de montagem. ${ }^{8}$

Mas, segundo os trabalhadores, há sim reclamação em relação a esses trinta minutos antes e depois da jornada de trabalho, e muitos já estão abrindo processo contra a empresa. A justiça do trabalho quer saber

[...] o que você faz, que horas você sai de casa, que horas você entra no ônibus, que horas você desce do ônibus, que horas você passa a sua carteirinha na catraca, o que você faz quando você entra dentro da empresa [Joana].

Entretanto, nem todos reclamam, pois, para muitos, prevalece o que é socialmente definido como tempo de trabalho, ou seja, como sinônimo de jornada de trabalho. É o que vemos claramente no diálogo a seguir, quando um trabalhador busca uma explicação no sentido de que esse tempo não se caracteriza como trabalho formal:

R: Eu chego na empresa entre 5h25, 5h30. Eu chego, vou para a produção, passo na produção, vejo tudo o que está produzindo. Porque devido ao trabalho da auditoria, a gente procura sempre estar vendo os problemas que podem ocorrer.

P: Mas a sua jornada começa a que horas?

R: Às $6 h 00$.

P: Mas então antes da tua jornada você já está trabalhando?

R: Eu passo só olhando, também não estou já trabalhando. Eu passo olhando, vendo se tem algum problema, sento junto com os líderes, é onde eles passam os trabalhos. [...] Ficamos mais ou menos umas dez ou cinco para as 6h00. Aí eu vou lá, tomo um café, às 6 h00 eu já começo a luta.

P: Agora esse tempo anterior, que você está conversando com os líderes, você não recebe por essas horas? 
R: Não. Não é bem um trabalho. [...] É a comunicação que você tem com eles.

P: E a comunicação é o que?

R: Praticamente se trabalha, mas isso é da gente, é da pessoa, nem todos fazem isso [Eron].

Esse não é um caso isolado porque muitos encarregados e líderes frisam que eles devem chegar de quinze a vinte minutos antes do turno e que outros devem ficar quinze minutos após o turno, pois, nesse tempo, são repassadas as informaçōes sobre o trabalho. Entretanto, no banco de horas só são depositadas as horas a mais que ultrapassem trinta minutos; assim, teríamos umas cinco horas de trabalho a mais por mês, por trabalhador, não remuneradas.

Vemos então que os trinta minutos antes e depois da jornada de trabalho exercem, na maior parte das vezes, um duplo papel. Um deles é de ser realmente um tempo de trabalho não remunerado. $\mathrm{O}$ outro é de cumprir o papel das pausas, cada vez mais reduzidas, isto é, de ser um tempo de conversa, de descontração, possibilitando maior conhecimento e entrosamento entre o grupo. Entretanto, a diferença fundamental é que as pausas formais, durante a jornada de trabalho, são consideradas como tempo de trabalho e são, portanto, remuneradas. Já os trinta minutos antes da jornada não são remunerados.

\section{As vivências fora do local de trabalho}

Neste tópico, analiso como os trabalhadores vivenciam seu tempo fora da fábrica, considerando a total inter-relação com o tempo em que passam no seu interior, uma vez que tanto a mudança quantitativa como a qualitativa de qualquer um desses tempos altera completamente o outro. Além disso, no contexto atual esses tempos sociais apresentam um movimento de reaproximação, sendo que os limites entre um e outro se tornam cada vez mais fluidos. O que os trabalhadores fazem fora do seu local e jornada de trabalho? Quanto tempo é dedicado à família, aos amigos, ao lazer, ao estudo e ao descanso? Como fazem para harmonizar os diversos tempos sociais? Quais momentos são privilegiados? Há ainda algum tempo dedicado ao trabalho profissional? Quais sentimentos e representaçōes expressam em relação ao tempo?
As sociedades contemporâneas caracterizam-se por um tempo urgente, acelerado e de mudanças contínuas, o que gera extremo mal-estar dada a dificuldade de harmonizar a crescente multiplicidade de tempos sociais (Bessin, 1999; Chesneaux, 1996). Com efeito, independentemente de idade, sexo ou função na empresa, as falas dos trabalhadores explicitam sentimentos ruins em relação à falta de tempo, à vida muito "corrida", "agitada" ou "acelerada" e ao conseqüente cansaço proveniente desse ritmo.

Os relatos deixam entrever que o fluxo tenso e intenso, característica principal do tempo dentro da fábrica, se estende para fora desta. Isto é, o trabalho repetitivo, monótono, sem autonomia, com um tempo imposto, ritmo acelerado, que desconsidera as necessidades dos trabalhadores e as diferentes disposiçôes ao longo do dia gera um cansaço que ultrapassa o espaço da fábrica. Isso ajuda a compreender por que os trabalhadores da Volkswagen, que têm uma jornada menor do que a prevista em lei, explicitem, com ênfase incomum, o sentimento de que o tempo de trabalho ocupa quase as 24 horas do dia.

A sensação de que falta tempo para a vivência social, sobretudo em relação à família, está muito presente. Se o tempo durante a semana é curto, o mesmo ocorre no final de semana, pois é este o momento para limpar a casa, estudar, ficar com a família, fazer compras, passear e descansar.

O sentimento de cansaço aparece ainda nas diferentes respostas sobre o que os trabalhadores gostariam de fazer a mais na vida e o que fariam, concretamente, no caso de uma redução da jornada de trabalho. Viajar aparece com grande destaque quando se trata de um desejo amplo, mas a resolução de demandas pessoais ou familiares mais urgentes ganham peso diante de possibilidades mais concretas e então "viajar" desaparece totalmente das respostas, sobressaindo a idéia de "descansar" e "estudar". Ou seja, as pessoas gostariam de viajar, mas, se tivessem uma redução da jornada de trabalho, iriam utilizar esse tempo para necessidades mais imediatas, como descansar e investir na formação profissional.

Viajar, então, fica restrito ao tempo livre das férias, mas nem sempre, pois segundo os trabalhadores é impossível fazer um planejamento, uma vez que a empresa os pressiona para saírem de férias somente em momentos de menor demanda: "se tem 
serviço você não sai de férias; se não tem serviço, você sai de férias, independentemente da sua vontade ou necessidade". Por outro lado, quase nunca eles conseguem conciliar as férias com a família, pois nenhum dos membros tem autonomia para definir os tempos de não-trabalho. Por fim, é preciso não esquecer do conflito entre as diversas demandas em relação ao tempo livre e à remuneração oriundos das férias, pois muitas vezes estes recursos são canalizados para estudo, reforma da casa, compra da casa ou do carro, entre outros.

Fora do local de trabalho, por sua vez, o pouco tempo livre ainda contém atividades relacionadas com o trabalho profissional, o que contribui para a sensação de vida corrida, cansaço e falta de tempo. Tais atividades englobam o tempo dedicado ao deslocamento da casa para o trabalho, às atividades de qualificação e também os momentos em que os trabalhadores buscam soluçôes e sugestôes para o processo de trabalho. Se tudo isso não pode ser nomeado como tempo de trabalho, não deve, por outro lado, ser entendidos como tempo livre, em que os sujeitos deveriam deter a liberdade de fazer o que quiserem.

Mesmo estando fora da empresa, a mente não para de pensar no trabalho, dizem muitos trabalhadores, um tempo dedicado à busca contínua de soluçôes para problemas enfrentados na empresa, de sugestões para a melhoria da produção, numa tentativa de se destacar, garantindo o emprego ou viabilizando uma promoção. Já houve um tempo para a discussão dos problemas da área e a busca de soluções dentro da empresa:

[...] hoje você tem que trazer de casa a sugestão. [...] Porque o tempo para a empresa é muito grande, porque ela quer melhoria em pouco tempo, que dá resultado para ela em pouco tempo. O tempo que a gente faz a melhoria, ela está ganhando [Carlinhos].

A preocupação em não perder o emprego perpassa a vida do trabalhador, o que pode levar a um investimento de tempo ainda maior com respeito ao estudo. Para aqueles que estudam, a rotina entre trabalho e faculdade é árdua - sair de casa às 4 h30 horas da manhã e voltar após às $22 \mathrm{~h} 00$ horas -, o que resulta num acúmulo de problemas com a família, em função da falta de tempo, mas também de renda, já que parte passa a ser destinada ao estudo. Como conseqüência, os trabalhadores com mais idade aludem à extrema dificuldade de estudar e vivenciar as outras temporalidades sociais, isto é, o tempo com filhos, família ou amigos durante a semana e no final de semana.

Voltar a estudar altera a vivência do tempo, tanto do ponto de vista quantitativo como qualitativo, em muito contribuindo para a sensação de vida corrida, pois, se o dia continua tendo uma duração de 24 horas e o salário recebido se mantém, o tempo e a renda antes dedicados a outras atividades serão reduzidos. Por seu turno, a empresa, ao mesmo tempo em que exige cada vez mais a volta aos estudos, não mais oferece os cursos ministrados no Senai, além de reduzir o número de bolsas de estudo. À pergunta se a empresa exerce algum tipo de pressão para voltar a estudar, um trabalhador respondeu:

Não. É assim, eu exerço o cargo de monitor na empresa. E alguns líderes não me pressionaram em nada. Eles aconselharam, que seria bom que eu fizesse uma faculdade, até mesmo para um eventual crescimento meu na empresa. Que não teria como eu crescer mais se não tivesse uma faculdade. Mas, pressão a empresa não faz não [Jorge].

Além do crescente tempo dedicado ao estudo, fora do local de trabalho temos ainda o tempo dedicado ao transporte que muito contribui para a falta de tempo livre. Um tempo não reconhecido socialmente como de trabalho e tampouco como tempo à disposição do empregador, não sendo, portanto, remunerado. Entretanto, no entendimento de alguns trabalhadores,

[...] a partir do momento que você se levanta para ir trabalhar e você pega o ônibus da firma, psicologicamente você já está trabalhando. Têm também a questão da obrigatoriedade de fazer determinada atividade em determinado tempo: se preparar para ir trabalhar, pegar o ônibus, isto é, você não têm a liberdade de fazer outras atividades neste tempo, senão você chega atrasado no trabalho [Anderson]. 
Outros trabalhadores, quando questionados sobre o tempo de transporte, evidenciam a existência de um diálogo interno entre o significado socialmente construído, que desvincula o tempo de transporte do tempo de trabalho, e o que vivenciam cotidianamente:

Ele [tempo de transporte] não deixa de ser [tempo de trabalho]. Você está voltando do teu trabalho, mas eu não considero como sendo um trabalho. Obviamente que quando eu chego na minha casa, eu falo: "acabei de chegar do trabalho". Obviamente que quando você chega, toca o telefone, alguém te liga: "mas eu acabei de chegar do trabalho". Ou seja, eu sai do trabalho a $1 \frac{112}{2}$ hora atrás, mas eu continuo no trabalho. É uma diferença, mas ao mesmo tempo, em exercício não, mas de certa forma sim, então é complicado te colocar isso [Luiza].

Por fim, no caso das mulheres casadas e com filhos, há ainda um grande tempo dedicado às tarefas da casa, considerando que o aumento da taxa de atividade profissional não pode mascarar a persistência da extrema desigualdade entre homens e mulheres tanto no que se refere à própria atividade profissional como às atividades domésticas (Hirata e Kergoat, 2003). Ou seja, como fica claro no relato das trabalhadoras da Volkswagen, a mulher não passou a dedicar um tempo ao trabalho profissional por ter antes se liberado do tempo dedicado ao trabalho doméstico, mas somou esses dois tempos, reduzindo e/ou comprimindo os outros tempos sociais dedicados ao lazer, ao estudo, ao descanso. Assim, a mulher se vê ainda mais pressionada pela sensação de falta de tempo.

\section{Consideraçóes finais}

Num contexto de mudanças fundamentais nos tempos de trabalho e de não-trabalho, o objetivo deste artigo foi compreender como têm se dado as vivências cotidianas dos trabalhadores em relação a esses tempos sociais, contextualizadas tanto no plano macrossocial, como no nível microorganiza- cional pelas transformações nas relações sociais nos locais de trabalho.

Analisei as narrativas discursivas dos trabalhadores da Volkswagen, buscando compreender como os diversos tempos sociais coexistem e como os trabalhadores elaboram equaçóes temporais que têm como objetivo harmonizar o conflito entre esses tempos. Ao combinar a análise voltada aos planos macrossocial e microorganizacional foi possível averiguar, ainda, a influência recíproca entre as vivências individuais, a negociação coletiva, a legislação vigente e a cultura temporal de uma determinada sociedade num dado momento histórico.

Vimos, então, que são inúmeras as transformaçôes no local de trabalho, com impactos sobre as vivências dos tempos sociais tanto dentro como fora da fábrica. Tais mudanças influenciam o tempo de trabalho de forma mais ou menos explícita, mais ou menos direta, ou mais ou menos intensa. Entretanto, apesar dessa diversidade, as mudanças verificadas no período entre os anos de 1995 e 2005 apontaram para a redução, mas, sobretudo, para a flexibilização e a intensificação do tempo de trabalho.

Foi possível verificar que as vivências dos trabalhadores em relação a essas mudanças expressam significados diferentes, como aceitação, alteração, negação, reclamação e negociação. Significados que variam segundo a vivência do tempo presente que, por sua vez, é influenciada por diversos fatores: setor de alocação e função; atributos pessoais (como sexo e idade) e também sociais (como escolaridade). O tempo passado - destacando-se a história de vida de cada um - e as expectativas do futuro exercem papel igualmente importante na vivência do tempo presente.

É nesse emaranhado de determinantes macrossociais, microinstitucionais e pessoais que são construídas as vivências temporais cotidianas dos trabalhadores da Volkswagen do ABC, e de cada um de nós.

As mudanças que alteram de maneira mais explícita e direta o tempo de trabalho -redução da jornada semanal, sua ampliação pelo uso de horas extras e flexibilização desse tempo - têm sido objeto de discussão entre os trabalhadores e matéria de negociação coletiva. Outras mudanças ocorreram de maneira mais indireta e implícita, em decorrên- 
cia de transformaçōes tecnológicas, organizacionais, gerenciais e da gestão das pessoas - esse foi o caso da multitarefa ou multifunção e também das células de produção. Esses temas, apesar de terem sido objeto de ampla negociação coletiva, no que se refere especificamente aos seus impactos no tempo de trabalho, apesar de amplamente criticados pelos trabalhadores, não foram objetos de negociação.

Há, também, mudanças que não foram apresentadas pelo movimento sindical como pauta de reivindicação. Podem até ter sido discutidas no local de trabalho, mas não se transformaram em reivindicação para negociação coletiva. Entre elas, destaca-se a dificuldade em criar uma pausa informal na nova linha de montagem dos carros Pólo e Fox. Isto é, o ritmo da linha foi mantido, mas se acabou com as porosidades utilizadas pelos trabalhadores para adiantar o trabalho e poder fazer pequenas pausas. Isso não se configurou em objeto de reivindicação coletiva, apesar de o ritmo das linhas continuar a ser alvo de intensa negociação entre empresa e sindicato.

De acordo com os trabalhadores, o que tem alterado mais profundamente o tempo de trabalho resulta da combinação entre duas formas de flexibilização: o banco de horas e a multitarefa. Essa combinação faz com que os trabalhadores estejam expostos a um tempo de trabalho intenso, a todo o momento, e em todos os espaços. Desse modo, nas fases em que a demanda por produção é baixa, ele é convidado a ficar em casa - para folgar as horas positivas do banco de horas ou tirar férias individuais e coletivas. Quando a demanda está alta, o trabalhador é convocado a trabalhar a mais, em função do banco de horas, sendo alocado naquela função, ou setor, onde há maior demanda de trabalho, situação possibilitada pela multifunção.

Tal combinação de flexibilização do tempo com atividade de trabalho tem como conseqüência a extrema intensificação do tempo de trabalho, adicionada às iniciativas para a redução das pausas coletivas e individuais. Em contraste, para a empresa, essa extrema flexibilidade permite remunerar apenas o tempo efetivamente trabalhado na linha de produção por um indivíduo que se torna, cada vez mais, e por mais tempo, disponível (Durand, 2004).

Os trabalhadores pesquisados relatam que o tempo de trabalho extrapola o espaço da fábrica do ponto de vista qualitativo e quantitativo. Em outras palavras, estabelece-se outra forma de relação entre os tempos dentro e fora da fábrica pela qual o tempo fora já não pode mais ser tomado como sinônimo de tempo livre.

Do ponto de vista qualitativo, o tempo de nãotrabalho é invadido pelo cansaço, pela sensação de que se trabalha o tempo todo e, conseqüentemente, a sensação de que o tempo livre é insuficiente, o que faz a vida se tornar muito "corrida". Do ponto de vista quantitativo, nas sociedades contemporâneas as pessoas passam a incluir um número cada vez maior de atividades no tempo liberado de jornada de trabalho, sendo algumas ainda relacionadas ao próprio trabalho (Grossin, 1991; Mercure, 1995; Sue, 1994). Isso leva à crescente dificuldade de harmonizar a multiplicidade cada vez maior de tempos sociais. Os jovens da Volkswagen, por exemplo, têm uma jornada de trabalho menor do que seus pais tinham, mas ocupam esse tempo liberado com o estudo.

A sensação de que o tempo de trabalho ocupa o dia todo - apesar dos trabalhadores da Volkswagen terem uma jornada menor -, também é conseqüência da existência de um tempo grande dentro da fábrica não considerado trabalho e, portanto, não remunerado, mas, do ponto de vista dos trabalhadores, tampouco podem ser denominados tempos livres, já que é imposto, determinado, e flui em espaços estabelecidos e com atividades igualmente estipuladas.

Ademais, há que se lidar com a preocupação em relação ao emprego, que persegue os trabalhadores mesmo quando estão fora da fábrica, imaginando formas para resolver os problemas do trabalho, em sua urgência por sugestôes para se destacar e manter-se no posto ou ascender na carreira. Todas essas preocupaçôes ocupam seu corpo e sua mente no pouco tempo restante fora do local de trabalho. Tempo invadido, ainda. por uma crescente flexibilização, que implica na perda de controle e de previsibilidade de quando irão (ou não) trabalhar, o que lhes desorganiza o tempo de não-trabalho.

Todos esses elementos geram uma sensação de extremo mal-estar num contexto temporal caracterizado pela urgência, tensão, intensidade, flexibilidade, incerteza e aceleração.

Entretanto, esta é a marca do tempo presente, mas não necessariamente do futuro. $\mathrm{O}$ tem- 
po de trabalho, assim como o do não-trabalho é uma construção social, o resultado da correlação de forças presente na sociedade em cada momento histórico. Isso permite pensar a sociedade - suas instituiçôes, regras e valores - como algo passível de mudança, de intervenção, reconstrução e transformação. Portanto o primeiro passo é analisar e discutir o que ocorre hoje no interior da fábrica. No que se refere especificamente à disputa em torno da jornada do trabalhador, é também importante refletir sobre os caminhos que tem tomado a questão relativa ao tempo de trabalho no Brasil nas últimas décadas, bem como suas conseqüências para a vivência individual e social dos tempos fora da fábrica.

\section{Notas}

1 Este artigo foi elaborado a partir de minha tese de doutorado Tempos de trabalho, tempos de não trabalho: vivências temporais cotidianas, 2007.

2 A Volkswagen do Brasil tem ainda quatro outras plantas, além desta no ABC. De acordo com Rodrigues (2002), trata-se da empresa montadora que, na década de 1990, apresentou um maior número de negociações sobre jornada de trabalho.

3 De acordo com Thoemmes (2000), também na França a redução do tempo de trabalho deixou de ser um tema discutido em si mesmo para se transformar em moeda de troca, seja pela flexibilização do tempo de trabalho, seja pela criação ou manutenção do emprego.

4 Na Volkswagen o trabalho em turnos de revezamento teve vigência até 1999. Os trabalhadores ficavam quinze dias em cada um dos três turnos, no caso do regime seis por um, e 45 dias no regime cinco por dois, em caso de apenas dois turnos. Após essa data, os trabalhadores puderam dizer em qual turno preferiam trabalhar.

5 O banco de dias foi implantado pela Volkswagen no início de 1998, ano em que a empresa ameaçou demitir 6.500 trabalhadores. Essa forma de flexibilização não foi aplicada em todos os setores, mas principalmente naqueles onde estavam ocorrendo mudanças na produção, como em toda a cadeia da Kombi e na implantação da linha do Pólo.

6 O ônibus da empresa chega sempre trinta minutos antes do inicio da jornada de trabalho e sai trinta minutos após o encerramento desta.
7 A empresa tirou os microônibus que levavam os trabalhadores aos seus respectivos setores, sendo mantidos apenas para aqueles que trabalham na Ala 17 .

8 Tal redução pode parecer pouco, mas quando multiplicada por 22 dias úteis resulta em quase duas horas por mês, por cada trabalhador (num total de 13 mil) que foram subtraídas pela empresa.

\section{BIBLIOGRAFIA}

ANTUNES, R. (1995), Adeus ao trabalho? Ensaios sobre as metamorfoses e a centralidade do mundo do trabalho. São Paulo, Cortez/Editora da Universidade Estadual de Campinas.

AZNAR, G. (1995), Trabalhar menos para trabalharem todos. São Paulo, Scritta.

BESSIN, M. (1998), "Le Kairos dans l'analyse temporalle". Temps et Contretemps, 32, Paris.

(1999), "Le temps, une question de pouvoir”. Mouvements, 2, jan.-fev., Paris.

BLASS, L. M. S. (1998), “Jornada de trabalho: uma regulamentação de múltipla escolha”. Revista Brasileira de Ciências Sociais, 13 (36): 67-78.

BRESCIANI, L. P \& CARDOSO, A. C. M. (1999), Entre o Fusca e o Mercosul: trabalho e relações industriais na Volkswagen do Brasil. Estudo elaborado para o Project on Transnational Labour-Management Dialogue and Labour Law and Labour Relations Branch (datilo.).

CARDOSO, A. C. M. (2009), Tempos de trabalho, tempos de não trabalho: disputas em torno da jornada do trabalhador. São Paulo, Annablume.

CARDOSO, A. C. M. \& CALVETE, C. (2007), "Jornada de trabalho: teoria e prática", in Dieese, Relaçôes e condições de trabalho no Brasil, São Paulo, Dieese.

CARDOSO, A. C. M.; CALVETE, C. e FIGUEIREDO, A. (2008), "Argumentos para a discussão da redução da jornada de trabalho no Brasil sem redução de salários". São Paulo, Dieese, Nota Técnica n. 66.

CARdoso, A. C. M.; CAlvete, C. \& SOCHACZEWSKI, S. (2007), "Reduzir a jornada é gerar empregos de qualidade”. São Paulo, Dieese, Nota Técnica n. 57. 
CARDOSO, A. C. M.; Jager, P. \& CAMARGOS, R. (2002), "A negociação da jornada de trabalho por meio do banco de horas". Roteiro para Seminário, São Paulo, Dieese.

CARDOSO, A. C. M. et al. (2004), Reduzir a jornada é gerar empregos. Campanha pela Redução da jornada de trabalho sem redução de salários. São Paulo, Dieese.

CHESNEAUX, J. (1996), Habiter lê temps présent, passé, futur: esquisse d'un dialogue politique. Paris, Bayard.

DAL ROSSO, S. (1996), A jornada de trabalho na sociedade: o castigo de Prometeu. São Paulo, LTr.

DIEESE ABC. (1987), "Autolatina: união contra quem?". Trocando em Miúdos, boletim n. 3

DURAND, J. P. (2004), La chaîne invisible. Travailler aujourd'hui: flux tendu et servitude volontaire. Paris, Seuil.

ELIAS, N. (1998), Sobre o tempo. Rio de Janeiro, Jorge Zahar Editor.

FRACALANZA, P. S. (2000), Redução do tempo de trabalho: uma solução para o problema do desemprego? São Paulo, tese de doutorado, Faculdade de Filosofia, Letras e Ciências Humanas da Universidade de São Paulo.

GIDDENS, A. (1995), Politica, sociologia e teoria social. São Paulo, Editora da Unesp. . (2003), A constituição da sociedade. São Paulo, Martins Fontes.

GROSSIN, W. (1991), Pour une science des temps: introduction à l'écologie temporelle. Octares, Nancy.

GUEDJ, F. \& VINDT, G. (1997), Le temps de travail, une histoire conflictuelle. Paris, Découverte et Syros.

HIRATA, H. (1987), "Vida reprodutiva e produção: família e empresa no Japão", in Kartchevsky A. et. al. (orgs.), O sexo do trabalho, Rio de Janeiro, Paz e Terra.

HIRATA, H. \& KERGOAT, D. (2003), "A divisão sexual do trabalho revisitada”, in M. Maruani e H. Hirata, As novas fronteiras da desigualdade: homens e mulheres no mercado de trabalho, São Paulo, Senac, pp. 111-123.

HOBSBAWM, E. J. (2000), Da Revolução Industrial inglesa ao imperialismo. Rio de Janeiro, Forense Universitária.

LALLEMENT, M. Temps, travail e modes de vie.
Paris: Presses Universitaires de France, 2003.

MERCURE, D. (1995), Les temporalités sociales. Paris, L'Harmattan.

MISPELBLOM, F. B. (1999), "Où commence, où s'arrête, le temps de travail”. Temps, Statut et Conditions du Travail. Journées de Sociologie du Travail, Speciale VII, Bologna, Franco Angeli.

RAMALHO, J. R. (1999), "Organização sindical e a instalação de novas fábricas do setor automotivo: o caso do sul fluminense", in I. J. Rodrigues (org.), Novo sindicalismo vinte anos depois, Rio de Janeiro/São Paulo, Vozes/Educ/Unitrabalho.

RODRIGUES, I. J. (2002), "Relaçôes de trabalho e ação sindical no ABC paulista nos anos 1990", in M. R. Nabuco, M. A. Neves e A. M. Carvalho Neto (orgs.), Indústria automobilistica: a nova geografia do setor produtivo, Rio de Janeiro, DP\&A.

SALERNO, M. S. (1998), Projeto de organizaçôes integradas e flexíveis: processos, grupos e gestão democrática via espaços de comunicaçãonegociação. São Paulo, Atlas.

SUE, R. (1994), Temps et ordre social: sociologie des temps sociaux. Paris, s.n.

THOEMMES, J. (1999), "La construction du temps de travail: normes juridiques ou normes sociales?”. Revue Droit et Société, 41: 15-32, Paris. . (2000), Vers la fin du temps de travail. Paris, Presses Universitaires de France. . (2001), "Négociation du temps de travail er régulations intermediaires: le cas de Volkswagen", in G. Groux (dir.), L'action oublique négocié: approches à partir des 35 heures, FranceEurope. Paris: L'Harmattan, pp. 127-143.

THOMPSON, E. P. (1967), "Time, work-discipline, and industrial capitalism”. Past \& Presente A Journal of Historical Studies, 38, dez., Oxford.

WHITROW, G. J. (1993), O tempo na história: concepçôes de tempo da pré-história aos nossos dias. Rio de Janeiro, Jorge Zahar Editor.

ZARIFIAN, P. (1996), "La notion de temps libre et les rapports sociaux de sexe dans le débat sur la réduction du temps de travail”, in $\mathrm{H}$. Hirata e D. Senotier, Femmes et partage du temps du travail, Paris, Syros. . (2001), Temps e modernité: le temps comme enjeu du monde moderne. Paris, L'Harmattan. 


\section{OS TRABALHADORES E SUAS VIVÊNCIAS COTIDIANAS: DOS TEMPOS DE TRABALHO E DE NÃO TRABALHO}

\section{Ana Claudia Moreira Cardoso}

Palavras-chave: Jornada de trabalho; Tempo de trabalho; Tempo de não-trabalho; Flexibilidade.

Este artigo é um estudo das vivências cotidianas de trabalhadores em relação aos tempos de trabalho e de não-trabalho. $\mathrm{O}$ locus de análise privilegiado é o espaço da fábrica, a Volkswagen do Brasil, em sua unidade de produção do $\mathrm{ABC}$ - São Paulo, exemplo emblemático de iniciativas e negociações dirigidas a flexibilizar e intensificar a jornada de trabalho. A análise concentra-se no período compreendido entre 1995 e 2005, quando foram intensas as mudanças com respeito à organização e gestão do tempo de trabalho. $\mathrm{O}$ artigo inicia com uma breve discussão sobre os modos de construção social do tempo de trabalho nas sociedades contemporâneas, apresentando o debate recente na sociedade brasileira. A seguir, aborda o contexto da Volkswagen do Brasil, analisando as vivências temporais cotidianas dos trabalhadores, dentro e fora do local de trabalho.

\section{WORKERS AND THEIR EVERYDAY EXPERIENCES REGARDING: WORK TIME AND NON-WORK TIME}

\section{Ana Claudia Moreira Cardoso}

Keywords: Working day; Work time; Non-work time; Flexibility; Unions.

This paper is a study of the daily life of workers regarding their experiences and discourses on work and non-work time. The workplace is the privileged locus of analysis. This paper examines the case of Volkswagen do Brasil in its ABC region assembly plant, in São Paulo state, an emblematic example of initiatives and negotiations driven to achieve flexible and intense work time. The period of analysis is 1995-2005, when most intense changes had taken place. The first part of this paper presents a concise discussion of time and work time as societal constructions in contemporary society and the actual debate in Brazil. The second part briefly discusses the context of Volkswagen do Brasil in order to analyze the workers daily temporal experience inside and outside the work place.
LES TRAVAILLEURS ET LEURS VÉCUS QUOTIDIENS: DES TEMPS DE TRAVAIL ET DE NON TRAVAIL

\section{Ana Claudia Moreira Cardoso}

Mots-clés: Journée de travail; Temps de travail; Temps de non travail; Flexibilité.

Cet article est une étude des vécus quotidiens des travailleurs par rapport au temps de travail et de non travail. Le locus privilégié d'analyse est l'espace de l'usine Volkswagen do Brasil, dans son unité de production de l'ABC - région qui regroupe trois villes dans la banlieu de São Paulo - qui est un exemple emblématique des initiatives et des négociations menées en vue de la flexibilisation et de l'intensification de la journée de travail. L'analyse se concentre sur la période comprise entre 1995 et 2005, lorsque les changements par rapport à l'organisation et à la gestion du temps de travail ont été intenses. L'article débute par une brève discussion des modes de construction sociale du temps de travail dans les sociétés contemporaines, et présente le récent débat sur ce sujet dans la société brésilienne. L'article aborde, ensuite, le contexte de la Volkswagen do Brasil et analyse les vécus temporels quotidiens des travailleurs à l'intérieur et à l'extérieur de leur lieu de travail. 